\title{
A nova classificação dos tumores da mama da OMS
}

\author{
The new WHO classification of breast tumors
}

José Eymard H. Pittella'; Alfredo J. A. Barbosa ${ }^{2}$

A classificação das neoplasias constitui um importante capítulo da Patologia, podendo-se destacar alguns de seus objetivos: ordenar o conhecimento atual, uniformizar a nomenclatura, permitir melhor reprodutibilidade de diagnósticos e agrupar as lesões de acordo com a histogênese. Do ponto de vista anatomoclínico, essas classificações também são importantes na área da Oncologia por contribuírem como um dado a ser levado em conta na estimativa da evolução clínica do paciente. Além disso, a uniformização da nomenclatura dos tumores é essencial para que os dados de frequência, evolução, tratamento e prevenção obtidos em regiões geográficas diferentes possam ser comparados.

A história da classificação de tumores pela Organização Mundial da Saúde (OMS) começou a tomar forma em 1952(7), quando o subcomitê do Comitê de Especialistas em Estatística da Saúde da OMS discutiu os princípios gerais que norteariam a classificação estatística de tumores e chegou à conclusão que, para assegurar a necessária flexibilidade e facilidade de codificação, seriam necessárias três classificações distintas, de acordo com: 1) sede anatômica; 2) tipo histológico; e 3) grau de malignidade. Um passo mais importante foi dado em $1956^{(5)}$, quando o Comitê Executivo da OMS aprovou uma resolução solicitando ao diretor-geral a avaliação da possibilidade da OMS organizar centros em vários países com o objetivo de coletar e classificar amostras histológicas de diferentes tipos de tumores, visando a adotar uma nomenclatura uniforme. Essa resolução foi aprovada na $10^{\text {a }}$ Assembleia Mundial da Saúde, em maio de $1957^{(6)}$ e, no mês seguinte, um Grupo de Estudos sobre a Classificação Histológica de Tipos de Câncer se reuniu na cidade de Oslo, na Noruega, para assessorar a OMS na implementação da resolução.

O Grupo de Estudos recomendou critérios para seleção das sedes dos tumores para estudo e sugeriu as seguintes diretrizes para orientar a classificação histológica e testar sua validade: 1) para cada sede e tipo de tumor, deve ser elaborada uma tentativa de classificação histopatológica por um grupo de especialistas; 2) a seguir, um laboratório considerado centro de referência e outros laboratórios colaboradores designados pela OMS avaliam as classificações propostas; 3 ) os laboratórios participantes trocam as preparações histológicas entre si, acompanhadas de informação clínica; 4) estabelece-se uma classificação com base no consenso; 5) posteriormente, uma ou mais reuniões periódicas são convocadas pela OMS para facilitar troca de opiniões e possíveis correções ou modificações da classificação. Como se pode ver, essas diretrizes, com algumas pequenas modificações, continuam válidas até hoje.

A primeira classificação histológica de tumores da OMS foi publicada em 1967 e incluiu os tumores do pulmão, seguida pela classificação dos tumores da mama, em 1968. De 1967 a 1981, 25 volumes foram publicados da série International Histological Classification of Tumours, abrangendo a classificação de tumores de diferentes sedes e sistemas anatômicos. Nos anos seguintes, novas edições de classificação de tumores foram publicadas com ampla aceitação internacional e, a partir de 2000, foi iniciada uma nova série intitulada World Health Organization Classification of Tumours. Essa série, além de padronizar

1. Professor titular de Patologia da Faculdade de Medicina da Universidade Federal de Minas Cerais (UFMG); neuropatologista do Serviço de Patologia do Hospital das Clínicas da Faculdade de Medicina de Ribeirão Preto da Universidade de São Paulo (HCFMUSP); editor adjunto do Jornal Brasileiro de Patologia e Medicina Laboratorial (JBPML).

2. Professor titular de Patologia da Faculdade de Medicina da UFMG; editor do JBPML. 
a classificação dos tumores e estabelecer critérios histopatológicos para o diagnóstico, incluiu informações sobre o código de morfologia da Classificação Internacional de Doenças para Oncologia (ICD-O), epidemiologia, distribuição por gênero e idade, localização, sintomas e sinais clínicos, radiologia, genética e fatores prognósticos e preditivos em resposta ao tratamento.

Em julho deste ano (2012), a International Agency for Research on Cancer (IARC), com sede na cidade de Lyon, na França, publicou a $4^{a}$ edição da classificação dos tumores da mama da $\mathrm{OMS}^{(2)}$, representando uma revisão atualizada da $3^{a}$ edição, publicada em $2003^{(4)}$. Duas outras edições já haviam sido publicadas anteriormente, uma em 1968 (acima mencionada) e outra em 1981. Diferentemente da $3^{\mathrm{a}}$ edição, a $4^{\mathrm{a}}$ edição é dedicada exclusivamente aos tumores da mama. Contendo cerca de 340 fotografias a cores, tabelas e figuras, e mais de 1.600 referências, a $4^{a}$ edição foi escrita com a colaboração de 90 especialistas de 24 países, incluindo, além de patologistas com especialização em patologia mamária, especialistas em patologia de partes moles, hematopatologia e dermatopatologia, e em oncologia clínica, cirurgia oncológica, radiologia, biologia molecular e genética. Os capítulos foram revistos e aprovados por um Comitê Editorial e um Comitê de Consenso, buscando assegurar que a classificação atual represente uma visão de consenso ampla para patologistas e oncologistas.

Em um artigo de atualização publicado neste fascículo do Jornal Brasileiro de Patologia e Medicina Laboratorial (JBPML)(1) a Dra. Helenice Gobbi, uma das colaboradoras da OMS da $4^{a}$ edição da classificação dos tumores da mama, destaca as mudanças trazidas pela nova classificação, com ênfase nas implicações diagnósticas e terapêuticas. O artigo inclui seis tabelas mostrando as modificações da atual classificação em relação à classificação de 2003, o que facilita a compreensão das modificações. Em relação aos biomarcadores e à classificação molecular dos tumores de mama, merecem ser salientados dois aspectos. São comentados os novos escores recomendados para avaliação imuno-histoquímica dos marcadores prognósticos em câncer de mama que são amplamente utilizados na rotina, como os receptores hormonais (estrógeno e progesterona) e o receptor do fator de crescimento epidérmico 2 (HER2). Quanto aos testes para classificação molecular, assinatura gênica e avaliação preditiva de recorrência do câncer de mama, que vão de encontro à ideia de integrar carcinogênese, subtipo intrínseco ou molecular (luminais A e B, HER2 e basal), sistema de graduação (baixo grau, grau intermediário e alto grau) e tipo histológico (tubular, ductal, mucinoso, lobular etc.)(3), embora sejam promissores, estão ainda em fase de estudos.

O JBPML é, com certeza, uma das primeiras revistas científicas a publicar um artigo comentando a nova classificação dos tumores e lesões proliferativas da mama, os quais representam uma das rotinas mais encontradas na prática da patologia cirúrgica.

\section{Referências}

1. GOBBI, H. Classificação dos tumores da mama: atualização baseada na nova classificação da Organização Mundial da Saúde de 2012. JBPML, v. 48, n. 6, p. 463-474, 2012.

2. LAKHANI, S. R.; ELLIS, I. O.; SCHNITT, S. J.; TAN, P. H.; VAN DE VIJVER, M. J. (Eds.). WHO classification of tumours of the breast. Lyon: IARC, 2012.

3. MASUDA, S. Breast cancer pathology: the impact of molecular taxonomy on morphological taxonomy. Pathol Int, v. 62, n. 5, p. 295-302, 2012.

4. TAVASSOLI, F. A.; DEVILLEE, P. (Eds). World Health Organization classification of tumours. Pathology and genetics of tumours of the breast and female genital organs. Lyon: IARC, 2003.

5. WHO Official Records, n. 68, p. 14, 1956, resolution EB17.R40.

6. WHO Official Records, n. 79, p. 467, 1957, resolution WHA10.18.

7. WHO Technical Report Series, 1952, n. 53, p. 45. 